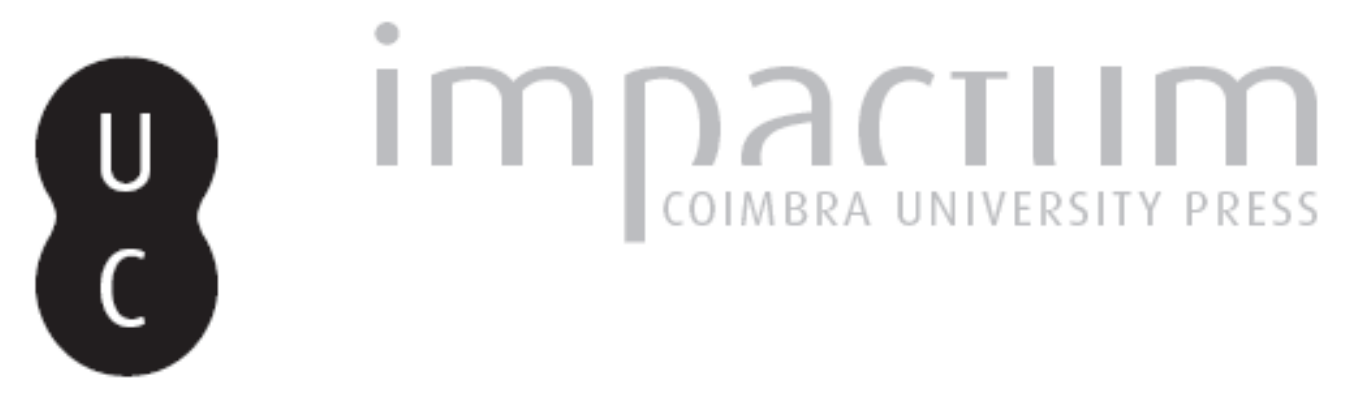

\title{
Filosofia e liturgia
}

\section{Autor(es): $\quad$ Cardita, Ângelo}
Publicado por: Faculdade de Letras da Universidade de Coimbra, Instituto de Estudos Filosóficos
URL persistente:
URI:http://hdl.handle.net/10316.2/33395
DOI:
DOI:http://dx.doi.org/10.14195/0872-0851_34_13

Accessed : $\quad$ 26-Apr-2023 03:20:08

A navegação consulta e descarregamento dos títulos inseridos nas Bibliotecas Digitais UC Digitalis, UC Pombalina e UC Impactum, pressupõem a aceitação plena e sem reservas dos Termos e Condições de Uso destas Bibliotecas Digitais, disponíveis em https://digitalis.uc.pt/pt-pt/termos.

Conforme exposto nos referidos Termos e Condições de Uso, o descarregamento de títulos de acesso restrito requer uma licença válida de autorização devendo o utilizador aceder ao(s) documento(s) a partir de um endereço de IP da instituição detentora da supramencionada licença.

Ao utilizador é apenas permitido o descarregamento para uso pessoal, pelo que o emprego do(s) título(s) descarregado(s) para outro fim, designadamente comercial, carece de autorização do respetivo autor ou editor da obra.

Na medida em que todas as obras da UC Digitalis se encontram protegidas pelo Código do Direito de Autor e Direitos Conexos e demais legislação aplicável, toda a cópia, parcial ou total, deste documento, nos casos em que é legalmente admitida, deverá conter ou fazer-se acompanhar por este aviso. 


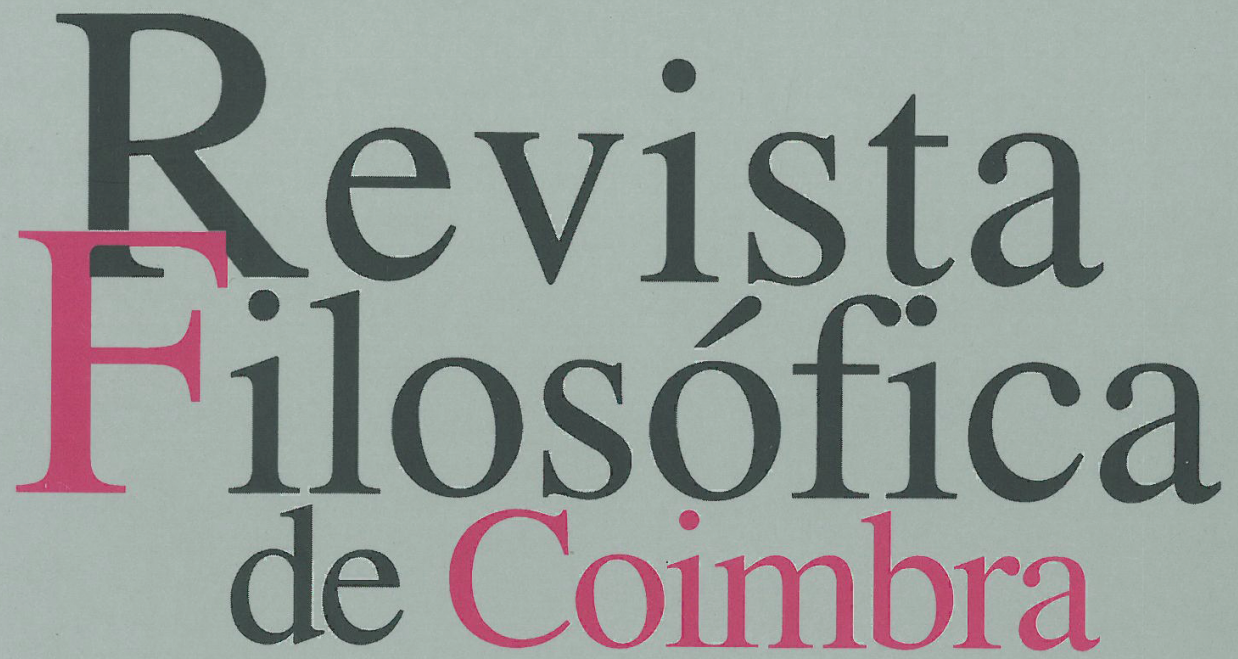

vol.17 | n.34 | 2008

José Reis

Manuel Moreira da Silva Helder Gomes

Filipe P. S. M. Menezes Edmundo Balsemão Maria João Silveirinha Luís António Umbelino Cláudio Alexandre S. Carvalho Armindo dos Santos Ana Isabel Boura Regina Queiroz Dulce Morgado Neves 


\title{
FILOSOFIA E LITURGIA
}

\author{
ÂNGELO CARDITA
}

(Unidade I \& D - L.I.F. - Linguagem, Interpretação e Filosofia, Faculdade de Letras da Universidade de Coimbra)

Durante três dias de intenso trabalho, de 20 a 22 de Maio de 2008, no Campus do Calvin College (Grand Rapids, Michigan, EUA), um grupo de cerca de sessenta filósofos, teólogos e antropólogos, movidos pelo convite de Nicholas Wolterstorff e dos seus colegas James K. A. Smith e John Witvliet, dedicou-se à reflexão e ao debate em torno do tema: Philosophy and Liturgy: Ritual, Practice, and Embodied Wisdom.

Não deixa de ser irónico que aquilo que no contexto português praticamente estéril no que respeita à filosofia e às ciências da religião - é tido como um tema de investigação vago e indeterminado seja proposto e indagado, noutros contextos, como um veio fértil e cheio de possibilidades para uma refundação da filosofia, das ciências da religião e da teologia. Naturalmente, este é só um dos exemplos da crise que as próprias ciências vivem no seu interior, quando começam a emergir "novos paradigmas", questionando as convicções "normais".

O quanto a filosofia pode ainda convocar os restantes saberes interessados na religião, desde a teologia às ciências sociais e humanas, abrindo-as não só às figuras concretas onde se faz a experiência religiosa e à vivência dos seus sujeitos (os crentes), mas também lançando-as para o encontro e o diálogo interreligiosos, ficou bem patente neste congresso.

E, no entanto, as perspectivas de investigação filosófica e interdisciplinar assim postas sobre a mesa, não se restringem às religiões e ao religioso. $\mathrm{Na}$ verdade, o interesse filosófico pelo rito não é uma novidade. O que é digno de nota nesta retomada é a sua explícita intenção revisora, pois fazendo do rito um tema de contemplação teórica, a filosofia faz trabalho de arqueologia, na busca dos próprios pressupostos do pensamento. E quando o pensamento se reencontra com as suas condições de possibilidade não haveria de renovar-se desde a raiz? Mais concretamente, 
este esforço dirige-se no sentido da superação das fracturas da modernidade, pela sua integração. Basta atender ao título deste Congresso para o intuir sob a forma de uma "sabedoria encarnada" (Embodied Wisdom).

$\mathrm{Na}$ conferência de abertura, Nicholas Wolterstorff (Philosophical Reflections on Liturgy: Getting Started) começou por chamar a atenção para a enorme discrepância entre as prioridades da filosofia analítica da religião e as dos crentes religiosos. Aqui, de facto, a experiência ritual e litúrgica aparece em primeiro plano, enquanto a filosofia se concentra nas cristalizações "dogmáticas" das crenças.

Como parte dos processos de enculturação, os seres humanos apreendem também meios de compreensão e de relação com Deus ou, se quisermos, com o sagrado. A liturgia é um destes meios. Mais concretamente, a liturgia deve ser considerada como uma prática social no seio da qual se pode perceber o aparecimento de standards de excelência na sua realização. A liturgia introduz então na existência humana a distinção entre a acção correcta e a acção errónea. Desta forma, mais que uma prática social genericamente entendida, a liturgia é uma prática específica, uma acção que segue um "guião" e, portanto, "prescrita" (scripted action). Naturalmente, é possível distinguir o guião da acção. Não é sequer necessário que o guião em questão esteja de facto escrito. O carácter de uma acção (ou conjunto de acções) que se desenrolam segundo um guião surge na superação dos próprios gostos e juízos dos actores, tal como na liturgia. Segundo Nicholas Wolterstorff, decidir participar numa liturgia é decidir adequar as próprias acções à norma do guião litúrgico. Quer dizer, o guião permite conjugar o carácter corporal com a dimensão comunitária: o guião coordena o movimento corporal com a acção comunitária. A prescrição do guião em relação à acção cria uma acção normativamente infundida (norm-infused).

A liturgia é, pois, para Nicholas Wolterstorff, uma sequência de acções normativamente infundidas através das quais os sujeitos religiosos entram em relação com Deus. Através destas acções a comunidade dos crentes conhece a primazia (worth) de Deus, por assim dizer, "enfrentando" Deus face-a-face (facing God). Com efeito, na assembleia litúrgica, os crentes dirigem-se a Deus (address God). Mas também Deus se dirige à assembleia. Na liturgia, os crentes não expressam (ou simbolizam ou comunicam) pensamentos orantes ou sentimentos sobre Deus, mais radicalmente, rezar a Deus é o que eles estão a fazer. O modelo "expressivo" é, portanto, inadequado à liturgia. A liturgia não é uma teologia aplicada. De facto, ela não é uma "aplicação" de todo, pois tem vida própria.

Missão do filósofo, dada a natureza da liturgia de acção prescrita por um guião, é a de descobrir a ratio implícita da mesma. Mesmo que algumas das acções rituais não tenham qualquer razão, um dos desafios para o filósofo é o da hermenêutica dos traços de actuação racional (rational agency) na liturgia. 
Josh Reeves (Embodied Knowledge: Some Reflections from Recent Philosophy of Science) propôs uma aproximação ao tema do Congresso desde uma reflexão sobre a filosofia da ciência, mais concretamente, desde a análise dos motivos que afastam a corporeidade do pensamento e este das efectivas práticas científicas. Para Reeves, há três motivos principais para esta situação: 1) a desatenção aos processos cognitivos levados a cabo sem o concurso da linguagem, com o consequente esquecimento da natureza sócio-económica do próprio conhecimento e o desafio da explicitação da localização do filósofo; 2) a diferença entre a inefabilidade da habilidade (skill) e o ideal da objectividade, quer dizer, o afastamento da implicação corporal na produção do conhecimento, concebido como uma "maquinização" em ordem a afastar os aspectos subjectivos; 3) o influxo do iluminismo, no sentido da eliminação do erro (não sem grande influência por parte da antropologia pessimista da reforma protestante).

O despertar do sono dogmático da filosofia da ciência deve-se, segundo Reeves, às perspectivas de Thomas Khun, principalmente na noção de "paradigma" que se deve entender propriamente no sentido de uma habilidade corporal (embodied) para encontrar soluções para os problemas, partilhada pela comunidade científica. Nesta visão não há lugar para a separação entre a teoria e as suas aplicações a situações concretas. Portanto, o conhecimento inclui também as suas dimensões tácitas e sociais.

Estes aspectos podem confluir numa atenção filosófica à vida religiosa e, concretamente, à liturgia. De facto, a habilidade é um aspecto importante na vida religiosa e na liturgia. $\mathrm{O}$ valor da liturgia reside mesmo na sua capacidade para repropor continuamente a necessidade de habilidades corporais (embodied skills) para o cumprimento da vida cristã. A liturgia não só reflecte a santidade pessoal do crente, como a produz. Um segundo aspecto prende-se com o papel transmissor, assumido pela comunidade, o que implica ainda a submissão a uma autoridade, como forma de aquisição de uma habilidade. Finalmente, a liturgia põe a questão da flexibilidade das habilidades adquiridas no contexto religioso, como critério de identidade, para além dos critérios teóricos (dogmáticos).

O encontro da liturgia com a filosofia - ou da acção ritual com o pensamento crítico - requer uma descrição completa e actual do rito e do tipo de intencionalidade religiosa que o caracteriza. Esta foi a tese que Ângelo Cardita (Ingenuity and Critique: On the Place and Necessity of Philosophy in Liturgy's Practice and Wisdom) ilustrou com a sua conferência. Na verdade, podemos aceitar que a acção ritual é um objecto integral e diversificado, exposto, portanto, a várias aproximações e perspectivas, sob a condição, no entanto, de que estas diferentes metodologias 
não entrem em contradição com o significado imediato e "ingénuo" do rito. Para demonstrar o entrelaçar de dimensões sócio-antropológicas, filosóficas e religiosas, Ângelo Cardita prestou atenção ao desenvolvimento recente do Magistério Católico sobre a liturgia, assim como à estruturação de uma teologia litúrgica e, finalmente, de uma filosofia da liturgia.

Na encíclica Mediator Dei, de 1947, a liturgia é definida como o culto de Cristo glorioso e o actual culto "público" da Igreja. Nesta definição, temos uma dimensão teológica - a liturgia como continuação do sacrifício de Cristo - sustentada por implícitos aspectos sócio-antropológicos e filosóficos, concretamente a visão da Igreja como uma sociedade hierárquica e a noção filosófica da virtude de religião. Para a constituição conciliar Sacrosanctum Concilium do Vaticano II (1962-1965), o fundamento filosófico da liturgia passa a ser "fenomenológico", e as suas condições socio-antropológicas são indicadas pelo imperativo da participação activa. Aliás, para este documento, a participação activa na liturgia de todos os fiéis constitui mesmo a mais alta manifestação da essência da Igreja. Com o recente Motu Proprio "Summorum Pontificum" de Bento XVI emerge um novo problema, pois não é possível pensar a liturgia simplesmente como uma "exterioridade" ritual e corporal, submetida a princípios racionais e dogmáticos, mas de facto mutuamente extrínsecos.

A liturgia católica é capaz de concretizar integralmente o moderno projecto pedagógico. A liturgia dá uma forma específica ao ideal social da Igreja. Era nestes termos que Isidro Gomá concebia a liturgia, numa obra do início do século XX. Já para Cipriano Vagaggini, todas as conclusões dedutivas da teologia podem encontrar-se de modo indutivo nos textos e acções litúrgicos. O conhecimento litúrgico não é, portanto, analítico ou reflexivo, mas "conatural", feito de emoções e sentimentos. Na situação pós-moderna, a secularização é a condição - ou pelo menos parte - do sentido religioso. É numa busca e numa construção intersubjectivas que o sentido emerge, segundo Graham Hughes. O sentido litúrgico resulta, assim, da interacção entre o que a liturgia propõe e o que os sujeitos trazem para a liturgia.

A "reverência" é uma resposta ao ser. Só o homem reverente se pode transcender a si mesmo, conformando-se à sua condição metafísica fundamental. Deste modo, para Dietrich von Hildebrand, a pessoa formada pela liturgia absorve no seu próprio corpo a noção de que deve responder adequadamente a cada valor. Susanne Langer estuda a simbolização enquanto acto essencial para o pensamento. O símbolo desempenha uma pura função "expressiva". A base conotativa da linguagem humana presente no rito mostra que o rito é a mais primitiva reflexão 
do pensamento. Na liturgia, Jean-Yves Lacoste encontra uma verdadeira "não-experiência" da experiência do mundo. Na liturgia, o ser-no-mundo não dá as coordenadas da experiência. O mundo mantém Deus na inevidência. Esta é a tensão viva da liturgia, uma vez que ela permite-nos ser-no-mundo-diante-de-Deus.

A leitura destes elementos aponta para a conclusão de que a filosofia é chamada a criar um "contexto" hermenêutico - em ordem à prática e à sabedoria litúrgicas - de tal forma que o "pretexto" da intencionalidade religiosa (que guia a teologia) possa ser reproposto em articulação com o "texto" sócio-antropológico.

Sara Coakley apresentou uma comunicação com o título: Beyond "Belief": Liturgy and the Cognitive Apprehension of God, colocando a questão: $\mathrm{O}$ que pode a filosofia da religião fazer com a ideia de que a liturgia não meramente relata, ou inculca, as crenças da fé cristã já conhecidas racionalmente, mas que em e por si mesma fornece um particular tipo de verdade? Com efeito, segundo Coakley, uma liturgia bem-conduzida dá-nos acesso a certo tipo de "verdade" que só a liturgia pode oferecer; uma verdade "completamente não proposicional".

Desenvolvendo as propostas de Alston, a filósofa apresentou a liturgia nos termos de uma "prática doxástica". As formas específicas, corporais, em que os cristãos procuram "perceber" Deus através da liturgia envolve um grupo de práticas ramificadas que não são forçosamente análogas à "percepção" numa resposta "imediata" a Deus, mas complexos meios de treino dos sentidos, ao longo do tempo, a fim de chegar a uma correcta relação com Deus. Este aspecto foi completado com alguns contributos oriundos da epistemologia feminista, principalmente a consciência de que sem relações primárias, sem mobilização afectiva no reconhecimento de rostos familiares, nunca progrediríamos para uma nomeação e negociação.

Chegada a este ponto, Coakley perguntou-se pelo tipo de instrumento epistemológico envolvido no processo litúrgico. Inspirada em Gregório de Nisa (que reconhece a possibilidade de treinar os sentidos físicos de tal forma que eles podem antecipar, de algum modo, as capacidades do corpo ressuscitado...), a filósofa defendeu que o que é distintivo do "conhecimento" litúrgico é a forma em que o movimento corporal, a acuidade sensual, a expectativa afectiva e a resposta noética ou intelectual se entrelaçam e implicam mutuamente. A Liturgia não é um complemento "afectivo" da reflexão intelectual, mas antes o meio de uma completa integração de todos os aspectos da identidade encarnada (embodied selfhood) na vida de Cristo.

James K. A. Smith (Philosophy of Religion Takes Practice: Liturgy as Source and Method in Philosophy of Religion) começou por chamar a 
atenção para os limites do renascimento na Filosofia da religião. A religião foi reintroduzida como um tópico de consideração e admitida como uma legítima perspectiva de orientação para a investigação e a reflexão filosóficas. O desenvolvimento de uma filosofia religiosa vem ao encontro da epistemologia reformada de Nicholas Wolterstorff e Alvin Plantinga, através da crítica da suposta neutralidade e autonomia da razão. Mas há uma lacuna: a ausência de qualquer atenção rigorosa à liturgia ou às práticas das comunidades religiosas. A filosofia da religião tem estado atenta às crenças mas não aos crentes, quer dizer, à experiência encarnada (embodied) da religião primeiramente como "forma de vida". Um aspecto central e formador desta forma de vida é a participação nas liturgias comunitárias, nas práticas rituais e outras formas de disciplina espiritual comuns. Enquanto os crentes se concentram na fé como modo de vida (aquilo que se faz), a filosofia da religião tende a tratá-la como modo de pensar (aquilo em que se acredita).

Julgando pelo estado da filosofia da religião, poder-se-ia pensar que a religião é obra de cérebros no vácuo, flutuando numa espécie de éter, mas nunca realmente atingindo as práticas das comunidades religiosas... Como resultado desta filosofia da religião centrada no cognitivo, a liturgia é tendencialmente pensada como uma ocasião expressiva das ideias religiosas previamente elaboradas. Mas isto é mesmo uma falsificação da religião.

Uma nova renascença na filosofia da religião poderia ser acendida invertendo esta suposição e levando a sério a prioridade das práticas litúrgicas em relação às formulações doutrinais. Isto implica desafiar a antropologia religiosa racionalista, tal como de facto a própria religião faz, exibindo uma forma de ser-no-mundo que manifesta a natureza fundamentalmente afectiva da pessoa humana. Aqui vislumbra-se uma relação dialéctica entre filosofia e liturgia: por um lado, a experiência viva encarnada na prática litúrgica aponta para a necessidade de uma antropologia filosófica "afectiva" (não racionalista); pelo outro, o desenvolvimento e integração deste tipo de reflexão habilita a filosofia da religião para aproximar-se dos fenómenos ligados à religião.

Uma "filosofia da liturgia" constitui, no entanto, apenas um aspecto da viragem metodológica que James Smith tem em mente. A prática e formação litúrgica, devem aparecer ainda como condição de possibilidade da própria filosofia da religião, quer dizer, uma "filosofia litúrgica" (Liturgical Philosophy). Trata-se de um prolongamento das críticas contra a "razão secular" na sua pretensão de absoluta autonomia e objectividade. Para James Smith, trata-se mesmo de um modelo "revelativo" ou "iluminativo" de filosofia religiosa. As revelações religiosas oferecem um depósito único de sabedoria (Wisdom) que é explorado e refinado 
pela reflexão filosófica. O futuro de uma filosofia pós-fundacionista, pós-liberal e pós-secular requer que a filosofia se volte para a liturgia, igualmente como tema (topic) e como princípio (fount) de reflexão. $\mathrm{O}$ ponto fulcral, aqui, é a recusa de qualquer dualismo entre teoria e prática.

O "imaginário social" (Charles Taylor) é mais uma espécie de "compreensão" não-cognitiva do que um "conhecimento" ou conjunto de crenças. É uma forma de entendimento do mundo enquanto significativo, mas não restrita às dimensões cognitiva e proposicional. É mesmo uma espécie de "intuição" capaz de evitar a articulação proposicional, transmitida por imagens, histórias e lendas. O imaginário social é não a forma como pensamos sobre o mundo, mas a modo como o imaginamos antes mesmo de pensar sobre ele. Esta proposta tem, pelo menos, duas consequências para a filosofia da religião: primeiro, em relação às fontes, significa que o dinamismo da crença religiosa funda-se primordialmente nas práticas e disciplinas das comunidades religiosas; segundo, em relação ao método, significa que o trabalho filosófico está inevitavelmente configurado e orientado pela "compreensão" pré-cognitiva do mundo. Deste modo, tal como uma compreensão está implícita na prática, assim também as práticas litúrgicas tornam-se a condição sine qua non para o desenvolvimento da filosofia da religião. Trata-se de uma compreensão implícita na prática que não pode ser apresentada separadamente da prática. Não se trata tanto de considerar a liturgia como expressão das crenças cognitivas, mas de considerar a liturgia como o seu princípio: as doutrinas são, assim, a articulação cognitiva daquilo que "compreendemos" quando rezamos e agimos ritualmente. A condição de possibilidade da filosofia da religião encontra-se não propriamente no conjunto de ideias ligadas às revelações religiosas, mas mais radicalmente na participação nas práticas litúrgicas das comunidades como meio de configuração da imaginação filosófica e daquilo que constitui a "racionalidade".

Reinhard Hütter (Lex Orandi - Lex Credendi: Eucharistic Transubstantiation in Light of the Adoration of the Blessed Sacrament) referiu-se à adoração eucarística como autêntica prática litúrgica (na Igreja Católica), num exercício da fé à procura do entendimento (fides quaerens intellectum). Mais concretamente, Hütter visou a interpretação tomista da "presença real". Com efeito, a intencionalidade desta prática litúrgica, em todos os seus componentes, foca-se exclusivamente no próprio "Santíssimo Sacramento". A interpretação filosófica requerida pela adoração eucarística deve, então, dar conta destes factos. E, para Hütter, o pensamento de Tomás de Aquino cumpre esta condição, recorrendo à contemplação metafísica para explicitar o mistério de fé (que constitui o 
principium da própria metafísica). A interpretação filosófica explicita assim o que a prática da Igreja confirma: a presença de Cristo no sacramento transcende o espaço e o tempo e, portanto, a própria "matéria" sacramental, mas, por isso mesmo, a sua presença pode aí permanecer.

Ludger Viefhues-Bailey (Displacing Bodies: Ritualization and Resistance) questionou as perspectivas ritológicas de Catherine Bell, particularmente a noção de "ritualização" (ritualization), para de seguida fazer uma análise de alguns segmentos rituais da liturgia católica. Partindo da interrogação sobre quem e o que se pode afirmar sobre a religião, como questão fundamental da filosofia da religião, Viefhues-Bailey assumiu como pressuposto que a prática litúrgica constitui em si mesma um discurso sobre o discurso religioso, na medida em que se caracteriza por um "consenso da acção" (Wittgenstein).

O conceito de ritualização faz com que a atenção se desvie das cristalizações do rito e suas representações mentais, para incidir no próprio acto ritual, nos seus dinamismos (tradição, criatividade, etc.) e, particularmente, no papel que os sujeitos assumem na sua realização. O rito é assim entendido como um particular modo de acção que estabelece a sua própria diferença, classificando, isto é, impondo hierarquias. O resultado é um sentido de totalidade e ordem, estreitamente ligado ao rito. O sujeito do rito é então submetido à sua eficácia através da própria acção e do próprio corpo, adquirindo, desta forma, um "sentido" - uma disposição - para o rito. O corpo que possui competência ritual realiza (performs) os actos ritualizadores de diferenciação e é produzido como agente ritualizado. Se pensarmos que o rito se dá ao nível social, então, o sujeito ritual deve ser entendido no sentido do corpo social. Será então possível resistir à força do rito? É neste sentido que Viefhues-Bailey se interroga sobre a forma em que a geração dos esquemas rituais afecta o tipo de identidade (self) criada pelo próprio processo de ritualização. A análise de três processos, pelos quais o tempo e o espaço convergem na configuração do agente ritualizado, na liturgia católica (a incensação das ofertas, a invocação do Espírito Santo epiclese - e a construção narrativa do tempo na oração eucarística), oferece os elementos para uma resposta. Viefhues-Bailey mostrou como o rito cria contrastes (clero-laicado), mas também como desestabiliza a centralidade dos sujeitos rituais, ao apelar à acção invisível de Deus (através do Espírito Santo). Os sujeitos rituais são então gerados numa fluidez constante - eles são estabelecidos, desestabilizados e restabelecidos. A multiplicidade e a instabilidade do corpo ritualizado consentem uma variedade de posições em relação ao rito, o que, para Viefhues-Bailey, é a condição de possibilidade da resistência ao mesmo. 
Para Peter Ochs (Redemptive Reasoning: Philosophy and Jewish Morning Prayer), a filosofia não é senão o desenvolvimento da razão na clarificação dos pressupostos e lógicas das várias práticas sociais, num sentido muito peculiar. Com efeito, a análise filosófica deve ser "convidada" pelo tema em questão. Ochs interessa-se assim em "responder" aos convites de "sofrimentos, problemas e disfunções". Neste tipo de convite ao pensamento, as condições de verdade ou falsidade dão-se no próprio problema. Por isso, a sua filosofia é "analítica" e "reparadora". O analista não pode, pois, referir-se a um determinado contexto sem participar do problema.

Neste sentido, situando-nos agora no contexto de um "pragmatismo escriturístico", Ochs - que é um filósofo judeu - considera que, para aqueles que recebem as escrituras como palavra de Deus, somos impelidos a empregar a razão de modo "reparador" e que o mundo de pretensões verdadeiras ou falsas é, de facto, reparador. Para o ilustrar, Ochs referiu-se à oração da manhã (shacharit) da sua tradição religiosa judaica. Mais especificamente, a análise concentrou-se nas transformações do "eu", motivadas pela oração. A oração começa por ratificar o "eu", por confirmá-lo na existência, cada manhã, em relação a um "tu" divino: "agradecido sou diante de ti". O juízo assenta na sabedoria, a qual começa pela relação com Deus: "o temor de Deus é o princípio da sabedoria". A reflexão transcendental sobre e a partir do "eu" conduz, assim, àquele que nos oferece a vida sempre de novo, cada manhã. Na verdade, as acções e os julgamentos do "eu" decorrem dessa relação e fazem descobrir a identidade como "alma animada" (nefesh): "louva o Senhor, ó minha alma". Tal como Deus se reveste de esplendor, assim o homem se veste (com o tallit), preparando-se para o dia de trabalho com tudo o que tem de encontros e compromissos com o mundo. A vida do "eu" imita as palavras e as acções do "tu" divino. Agora, o "eu" pode transformar-se em "nós": "escuta, Israel, só Hashem é o nosso Deus". O carácter reparador aparece com a doxologia, convidando o "eu penso", o "nós pensamos" a participar do "Ele pensa". O orante é convidado à presença de Deus e, nesse momento, os anjos declaram: "santo, santo, santo é Hashem". O orante, "eu" (fiel) e "nós" (Israel) participam, pois, da palavra e da acção daquele que redime, a quem se dirige a oração. Participam da personalidade daquele que escuta e responde aos clamores da oração. Transformando-se em dom e obrigação, a oração da manhã convida um pensamento pragmático reparador.

Terence Cuneo (If These Walls Could Only Speak: Icons as Vehicles of Divine Discourse) interrogou-se acerca dos ícones das igrejas orientais, particularmente sobre aquilo que, eventualmente, justifica o seu uso litúrgico. Nem a explicação "didáctica", nem o reconhecimento do seu carácter "quasi-sacramental" oferecem uma explicação cabal. Para Cuneo, 
os ícones devem ser antes entendidos como veículos da acção divina, mais particularmente como discurso divino. Os ícones assumem várias funções litúrgicas: testemunham a acção de Deus no mundo, mediam a sua presença e fazem participar nos eventos fundantes da fé. Portanto, se entendermos o modo em que os ícones são testemunhas, também abriremos caminho para a compreensão da sua função mediadora e participante. O testemunho divino pode ser entendido como um caso de "discurso de dupla-acção" (double-agency discourse), de resto tal como as escrituras, onde Deus fala apropriando-se do discurso humano. Os ícones, segundo a tradição, são meios pelos quais a igreja testemunha a encarnação do Verbo de Deus. Mas, mais radicalmente, transmitindo as intenções de Deus, os ícones são mediadores da sua presença no mundo. Neste sentido, os ícones dariam ocasião a verdadeiros "actos ilocutórios intencionais". Os ícones tornam-se mediadores da presença de Deus ao patentear as intenções dos actos ilocutórios de Deus para a humanidade. Assim sendo, no reconhecimento destas duas dimensões, participa-se na realidade dos eventos representados pelo ícone, na medida em que essa realidade molda a nossa própria identidade. Os ícones podem, pois, ser entendidos como os meios visuais pelos quais somos convidados (por Deus, na medida da apropriação do discurso humano) a configurar as nossas identidades narrativas em conexão com os eventos fundantes da fé.

A riqueza de perspectivas, métodos e ideias que o Congresso de Grand Rapids proporcionou vai mais além do que foi possível recolher nesta breve crónica. Mas se ela conseguir abrir caminho no sentido da discussão que ali teve lugar, então terá cumprido o seu principal objectivo. Mais concretamente, e de forma sintética, podemos dizer que a filosofia da religião depara-se agora com o desafio da revisão dos seus pressupostos e métodos num confronto privilegiado com as práticas religiosas e litúrgicas. Isto obriga também ao encontro interdisciplinar, pelo menos com a antropologia e a sociologia, por um lado, e com a teologia, pelo outro. Mas o horizonte deste encontro deverá ser verdadeiramente interreligioso e, portanto, verificável sob o terreno do efectivo contributo das religiões para a construção da humanidade. 